\title{
Thermal and Microwave-Assisted Oxidative Degradation of Poly(ethylene oxide)
}

\author{
S. P. Vijayalakshmi, J. Chakraborty, Giridhar Madras \\ Department of Chemical Engineering, Indian Institute of Science, Bangalore 560012, India
}

\begin{abstract}
The kinetics of the thermal and microwaveassisted oxidative degradation of poly(ethylene oxide) were determined with potassium persulfate as the oxidizing agent. Gel permeation chromatography was used to determine the variation of the molecular weight with time. The degradation was studied as a function of the temperature and persulfate concentration, and it was found that the degradation rate increased with the temperature and concentration of persulfate. Continuous distribution kinetics
\end{abstract}

were used to determine the rate coefficients for the degradation process, and the activation energies were obtained. The results indicated that the microwave-assisted process had a lower activation energy of $10.3 \mathrm{kcal} / \mathrm{mol}$, whereas that of the thermal degradation was $25.2 \mathrm{kcal} / \mathrm{mol}$.

Key words: activation energy; degradation; water-soluble polymers

\section{INTRODUCTION}

Polymer degradation is a subject of current interest in polymer science because of increasing environmental concerns. Pyrolysis is a common method that is used for studying polymer degradation. The current emphasis is the degradation of polymers in solution, ${ }^{1-4}$ rather than by pyrolysis, because of several advantages. The kinetics of the degradation process in solution can be monitored by the change in the molecular weight with time. A growing interest in nonconventional methods of polymerization and depolymerization has led to research on applications of microwaves for these processes. Microwave heating offers increased reaction rates and reduced electrical consumption, in comparison with thermal heating, as observed in several organic synthesis reactions. 5,6 There is a better distribution of heat in a sample and hence better control over the process. Moreover, the efficiency of converting electrical energy into thermal energy is over $85 \%$, and the rate of heating is many times faster than that of thermal heating. ${ }^{7}$

The degradation rate of polymers is important when there are additional components in the commercial polymer samples that gradually degrade the polymer with time. Persulfates are one such class of components, and they have wide industrial applications. They are used mainly as initiators for polymerization

Correspondence to: G. Madras (giridhar@chemeng.iisc. ernet.in). processes, as bleaching agents in photographic applications, in the preparation of adhesives, as dispersants for inks and toners, and in the preparation of special papers. ${ }^{8}$ These applications also use water-soluble polymers such as poly(ethylene oxide) (PEO) and polyacrylamide as the main ingredients of the process. Therefore, the fate of polymers in the presence of persulfates is an important issue to be considered. Persulfates are known to be powerful oxidizing agents and have been used in the oxidation of alcohols and diethyl and diphenyl sulfoxides in aqueous solutions. ${ }^{9,10}$ The decomposition kinetics of persulfates are $\mathrm{pH}$-dependent, and the order of the decomposition is close to one. In an alkaline medium, they are known to form sulfate and bisulfate anions, which upon heating produce radicals. ${ }^{11-13}$ It is well known that radicals have an adverse effect on polymer stability. The decomposition of persulfate anions occurs as follows:

$$
\begin{aligned}
\mathrm{S}_{2} \mathrm{O}_{8}^{2-} & \rightarrow 2 \mathrm{SO}_{4}^{-} \\
\mathrm{SO}_{4}^{-}+\mathrm{H}_{2} \mathrm{O} & \rightarrow \mathrm{HSO}_{4}^{-}+\mathrm{OH}
\end{aligned}
$$

The thermal degradation of polymers proceeds either by chain scission in the polymer backbone or by the unzipping of the monomer from the main chain. New end groups are formed that can be quantitatively and qualitatively determined by various techniques such as titration, viscometry, and spectroscopy. ${ }^{14}$ The average concentration of end groups produced upon the degradation of PEO by persulfates has been determined viscometrically with respect to the viscosityaverage molecular weight. The deviation from linear- 
ity of the difference in the viscosity versus time at short times has been related to the disentanglement kinetics in solution. ${ }^{15}$ The addition of strong acids and certain heavy metal ions has been found to be detrimental to the solution stability of PEO, whereas the addition of an alcohol such as isopropyl alcohol retards the degradation process. ${ }^{16}$ Thus, it is important to study the degradation of $\mathrm{PEO}$ in the presence of persulfates.

Degradation can be accomplished with thermal or microwave processes. Heating due to the microwave effect arises when polarizable molecules tend to reorient and align themselves in an applied microwave field. The ability to convert microwave energy into thermal energy depends on the dielectric constant and dielectric loss associated with a material. ${ }^{17}$ Microwave heating does not alter the composition of products appreciably in comparison with conventional heating techniques. ${ }^{18}$ The pyrolysis of lignin and cellulose was manipulated to improve product selectivity by rapid homogeneous heating by microwaves. Degradation rate enhancement during pyrolysis was also observed. ${ }^{19,20}$ The surface oxidation of polyethylene with permanganate was studied with Fourier transform infrared when microwaves were made to impinge on solid samples. ${ }^{21}$ Starch degradation in microwaves was studied by Khan et al. ${ }^{22}$ The hydrolysis of starch occurred at high temperatures and pressures produced in a sealed glass ampule, with an increase in the total acidity and a concurrent decrease in the $\mathrm{pH}$. The thermooxidative degradation of edible fats by microwaves and conventional heating was studied. A greater number of alterations occurred on microwaveheated samples, as quantified by chromatographic techniques. ${ }^{23}$ Polymerization reactions were also carried out with microwaves. ${ }^{24,25}$ Microwave polymerization of methyl methacrylate showed a marked dependence on the microwave power. ${ }^{26}$ The emulsion polymerization of styrene showed that the monomer/ water ratio, microwave power, volume of the reaction mixture, and geometry of the vessel used were important factors to be considered for accelerating heating rates. ${ }^{18}$

In this investigation, the thermal degradation of PEO in solution by thermal and microwave heating was examined by the addition of an oxidizing agent such as potassium persulfate. The effects of the persulfate concentration, reaction temperature, and different microwave heating cycle times on the degradation rate were studied. The rate coefficients were calculated with a model based on continuous distribution kinetics. The activation energy was obtained for thermal degradation from an Arrhenius plot and for microwave heating by a nonlinear regression of experimental data. A comparison of the rate coefficients and activation energies, which were obtained from thermal and microwave heating, was carried out to determine the effect of microwave radiation on polymer degradation in solution.

\section{EXPERIMENTAL}

\section{Materials}

PEO (Aldrich Co., St. Louis, MO) and potassium persulfate (S. D. Fine Chemicals, Bangalore, India) were used as obtained.

\section{Thermal degradation experiments}

The polymer was dissolved in double-distilled deionized water, and the concentration was $2 \mathrm{~g} / \mathrm{L}$. The concentration of potassium persulfate was varied from 0.2 to $1 \mathrm{~g} / \mathrm{L}$. The polymer solution $(15 \mathrm{~mL})$ was placed in culture tubes with screw caps. The temperature was maintained with a thermostated water bath controlled by a proportional integral derivative (PID) controller, and the variation in the temperature was $\pm 1^{\circ} \mathrm{C}$. The experiments were conducted from 40 to $70^{\circ} \mathrm{C}$. The tubes were placed in the water bath until it reached the desired temperature, and then persulfate was added to the polymer solution. A control experiment was also performed at each temperature to ensure that no degradation of the polymer occurred without persulfate.

\section{Microwave reactor}

A domestic microwave oven with a magnetron source for microwave generation was used (Essentia, Mumbai, India). The maximum power was $700 \mathrm{~W}$, and the frequency was $2.45 \mathrm{GHz}$. All experiments were conducted at the maximum power of the equipment.

\section{Microwave degradation experiments}

The polymer solution concentration was $2 \mathrm{~g} / \mathrm{L}$. The reaction vessel was a $50-\mathrm{mL}$ glass beaker. The volume of the solution was $40 \mathrm{~mL}$ for all the experiments. Three different concentrations of persulfate were used. The required persulfate was added and stirred to dissolution before the irradiation of the sample polymer solution was begun. The sample was placed at the center of the oven directly below the magnetron source. Different microwave cycle times [i.e., times of heating $\left.\left(t_{h}{ }^{\prime} \mathrm{s}\right)\right]$ were employed, such as 10,15 , and $20 \mathrm{~s}$, and the number of cycles was fixed at 10 . Therefore, for 10-, 15-, and 20-s, cycles, the total irradiation times were 100, 150, and $200 \mathrm{~s}$. To ensure uniform heating and to avoid temperature gradients, we rotated the sample on a turntable. The temperature of the reaction mixture was monitored with a fluoro-optic thermometer with an accuracy of $\pm 0.5^{\circ} \mathrm{C}$. The irradiated sample was cooled to $22^{\circ} \mathrm{C}$ by immersion in an ice bath for 
a set time of $110 \mathrm{~s}$ [i.e., cooling time $\left(t_{c}\right)$ ]. The temperature profile during heating in the microwave oven is given elsewhere. ${ }^{27}$ Samples collected at regular intervals were analyzed by gel permeation chromatography, as described elsewhere. ${ }^{28}$

\section{RESULTS AND DISCUSSION}

\section{Theoretical model}

The model described here is similar to a model described previously. ${ }^{27}$ The homolytic cleavage of persulfate into two radicals can be written as follows:

$$
\mathrm{C}_{2} \stackrel{k_{p}}{\rightarrow} 2 \mathrm{C}^{*}
$$

where $k_{p}$ is the rate coefficient for persulfate decomposition. The rate of persulfate disappearance by dissociation is

$$
\frac{d c_{p}}{d t}=-k_{p} c_{p}
$$

where $c_{p}$ is the molar concentration of persulfate. The hydrogen abstraction from polymer chains occurs through these radicals:

$$
\mathrm{C}^{*}+\mathrm{P}(x) \stackrel{k_{d}}{\rightarrow} \mathrm{CH}+\mathrm{R}^{*}(x)
$$

where a polymer, $\mathrm{P}$, of molecular weight $x$ breaks into radical $R^{*}$. The population balance for the consumption of persulfate radicals, $c$, at any time, $t$, can be written in terms of the polymer concentration, $p$, as follows:

$$
d c(t) / d t=-2 k_{p} c_{p}(t)-c(t) \int_{0}^{\infty} k_{d}\left(x^{\prime}\right) p\left(x^{\prime}, t\right) d x^{\prime}
$$

where $k_{d}$ is the rate coefficient for hydrogen abstraction. The temperature variation during microwave heating was found to vary linearly with time. The temperature profile for each cycle can be assumed to be

$$
T= \begin{cases}T_{w}+\frac{T_{\text {peak }}-T_{w}}{t_{h}} t & \forall t \in\left(0, t_{h}\right) \\ T_{\text {peak }}-\frac{T_{\text {peak }}-T_{w}}{\tau-t_{h}}\left(t-t_{h}\right) & \forall t \in\left(t_{h}, \tau\right)\end{cases}
$$

where $\tau$ is the total time, $t_{h}+t_{c}$. $T_{w}$ is the temperature of the water bath, and $T_{\text {peak }}$ is the maximum temperature reached at the end of heating cycle:

$$
\begin{gathered}
\mathrm{P}(x) \underset{k_{b}}{\stackrel{k_{a}}{\rightleftharpoons}} \mathrm{R}^{*}\left(x^{\prime}\right)+\mathrm{R}^{*}\left(x-x^{\prime}\right) \\
\mathrm{P}(x) \underset{k_{H}}{\stackrel{k_{h}}{\rightleftharpoons}} \mathrm{R}^{*}\left(x^{\prime}\right) \\
\mathrm{R}^{*}(x) \stackrel{k_{s}}{\rightarrow} \mathrm{R}^{*}\left(x^{\prime}\right)+\mathrm{P}\left(x-x^{\prime}\right)
\end{gathered}
$$

The initiation and termination that occur during polymer degradation are represented by eq. (8), the hydrogen abstraction from the polymer chain is represented by eq. (9), and the depropagation step that occurs by the irreversible $\beta$ scission of the polymer chain is shown in eq. (10). The initiation and termination steps are much less frequent than the depropagation steps and can be neglected. Thus the population balance equations for the concentrations of the polymer, $p$, and polymer radical, $r$, are given by

$$
\begin{array}{r}
\partial p(x, t) / \partial t=-k_{d}(x) c(t) p(x, t)-k_{h}(x) p(x, t)+k_{H} r(x, t) \\
+\int_{x}^{\infty} k_{s}\left(x^{\prime}\right) r\left(x^{\prime}, t\right) \Omega\left(x, x^{\prime}\right) / d x^{\prime} \\
\partial r(x, t) / \partial t=k_{d}(x) c(t) p(x, t)+k_{h}(x) p(x, t)-k_{H} r(x, t) \\
-k_{s}(x) r(x, t)+\int_{x}^{\infty} k_{s}\left(x^{\prime}\right) r\left(x^{\prime}, t\right) \Omega\left(x, x^{\prime}\right) / d x^{\prime}
\end{array}
$$

For random chain scission, the stoichiometric kernel, $\Omega\left(x, x^{\prime}\right)$, is given by $1 / x^{\prime} .{ }^{29}$ If we apply the moment operation to eqs. (11) and (12), we obtain

$$
\frac{d p^{(j)}}{d t}=-k_{d} c(t) p^{(j+1)}(t)-k_{h} p^{(j+1)}+k_{H} r^{(j+1)}+\frac{k_{s}}{j+1} r^{(j+1)}
$$

$$
\begin{aligned}
\frac{d r^{(j)}}{d t}=k_{d} c(t) p^{(n+1)}(t)+k_{h} p^{(j+1)}- & k_{H} r^{(j+1)} \\
& -k_{s} \frac{j}{j+1} r^{(j+1)}
\end{aligned}
$$

The quasi-steady-state approximation, which assumes that the change in the radical concentration is zero, can be applied to eq. (14), and the radical concentration is

$$
r^{(j+1)}=(j+1) p^{(j+1)} \frac{k_{d} c(t)+k_{h}}{j k_{s}+(j+1) k_{H}}
$$

The simultaneous solution of eqs. (13) and (15) gives the $j$ th moment in terms of known quantities: 


$$
\frac{d p^{(j)}}{d t}=-(j-1) k_{s} \frac{k_{d} c(t)+k_{h}}{j k_{s}+(j+1) k_{H}} p^{(j+1)}
$$

When $j$ is 0 , the zero moment representing the molar concentration of the polymer is

$$
\frac{d p^{(0)}}{d t}=k_{0} p^{(1)}
$$

where the overall rate coefficient, $k_{0}$, is given by $k_{\text {oxd }} c(t)+k_{\text {therm }}$. The oxidative degradation coefficient, $k_{\text {oxd }}$ is $k_{d} k_{s} / k_{H}$, and the thermal degradation coefficient in the absence of persulfate, $k_{\text {therm }}$ is $k_{d} k_{s} / k_{H}$. Because no degradation occurred in the absence of persulfate, the contribution from thermal degradation can be neglected, and so $k_{0}$ is equal to $k_{\text {oxd }} c(t)$. Thus, eq. (17) becomes

$$
\frac{d p^{(0)}}{d t}=k_{\mathrm{oxd}} c(t) p^{(1)}
$$

The first moment, $j=1$ in eq. (16), indicates that the mass concentration does not change with time. The simultaneous solution of eq. (18) along with eqs. (4) and (6) gives the time evolution of the number-average molecular weight $\left(M_{n}\right)$ with the initial set conditions and temperature dependence [eq. (7)].

\section{Thermal degradation in solution}

Thermal degradation experiments of PEO in solution in the presence of persulfate were performed at four different temperatures. No degradation of the polymer was observed even at $70^{\circ} \mathrm{C}$ within the reaction time in the absence of persulfate. The presence of persulfate drastically reduced the stability of the polymer in solution because it caused oxidative degradation. The temperature also had a major effect on the reaction kinetics. Degradation increased with temperature, and this could have been due to greater decomposition of persulfate at higher temperatures. ${ }^{11-13}$ However, as discussed by Price and Clifton, ${ }^{30}$ the thermal decomposition of persulfate is kinetically insignificant below $50^{\circ} \mathrm{C}$, and so polymer degradation occurred primarily because of oxidation.

Because thermal degradation occurred at a constant temperature, eqs. (4), (6), and (18) could be solved simultaneously, and the analytical solution is given by

$$
\begin{aligned}
& \frac{M_{n 0}}{M_{n}}-1 \\
& =M_{n 0}\left[\frac{2 c_{p 0} k_{\text {oxd }}\left(k_{d}\left(1-e^{-k_{p} p^{(1)} t}\right)+\left(e^{-k_{p} t}-1\right) k_{d} p^{(1)}\right)}{k_{d}\left(k_{p}-k_{d} p^{(1)}\right)}\right]
\end{aligned}
$$

where $M_{n}$ is the number-average molecular weight, given as $M_{n}=p^{(1)} / p^{(0)}$, and $M_{n 0}$ is the initial numberaverage molecular weight.

Although the rate coefficients and activation energies for hydrogen abstraction and random oxidative chain scission could be determined by the nonlinear regression of experimental data with the previous equation, we could simplify the equation by noting $k_{p}$ $\ll 1^{11}$ and $k_{d} p^{(1)} t \gg 1$. Linearizing the exponential and applying the assumptions, we reduced eq. (19) to

$$
\frac{M_{n 0}}{M_{n}}-1=k t
$$

where

$$
k=\frac{2 M_{n 0} c_{p 0} k_{s} k_{p}}{k_{H}}=k_{r} c_{p 0}
$$

where $c_{p 0}$ is the initial concentration of persulfate. Equation (20) is similar to the equation obtained by da Trindade Neto et al., ${ }^{15}$ who investigated the oxidative degradation of PEO by end-group analyses. The previous equation indicates that a plot of $\left[\left(M_{n 0} / M_{n}\right)-1\right]$ versus time would be linear, with the slope representing the rate coefficient $k$. Figure $1(\mathrm{a}, \mathrm{b})$ shows the variation of the molecular weight of PEO for two different concentrations of persulfate at different temperatures. The activation energy for the degradation, calculated from the Arrhenius dependence of the rate coefficient (Fig. 2), was $25.2 \mathrm{kcal} / \mathrm{mol}$. The activation energy for $k_{\text {oxd }}$ can be represented by the activation energies for $k_{s}, k_{p}$, and $k_{H}$ as $E_{s}+E_{p}-E_{H}$, respectively. Because the activation energy for persulfate decomposition, $E_{p}$, is $33.5 \mathrm{kcal} / \mathrm{mol},{ }^{11} E_{H}-E_{s}$ is $8.3 \mathrm{kcal} / \mathrm{mol}$. The values of $E_{d}$ and $E_{d}+E_{p}-E_{H}$ for the oxidative degradation of poly(vinyl acetate (PVAc) are 24 and $20 \mathrm{kcal} / \mathrm{mol}$, respectively. ${ }^{29}$ This indicates that $E_{H}-E_{s}$ is $4 \mathrm{kcal} /$ mol, which is comparable to the values obtained in this study.

Figure 1(c) shows the variation of the molecular weight at various values of $c_{p 0} 60^{\circ} \mathrm{C}$. A higher concentration of persulfate in the solution caused faster degradation of the polymer because there was an increase in the number of radicals formed from persulfate when it was present in greater amounts, and this increased the rate of degradation. A plot of $k$ versus $c_{p 0}$ is linear (Fig. 3). This observation is consistent with eq. (21), and $k_{r}$ is obtained from the slope of the linear plot. The value of $k_{r}$ is, of course, independent of the persulfate concentration.

\section{Microwave-assisted degradation in solution}

The microwave-assisted oxidative degradation of PEO was studied for different heating cycle times, which 


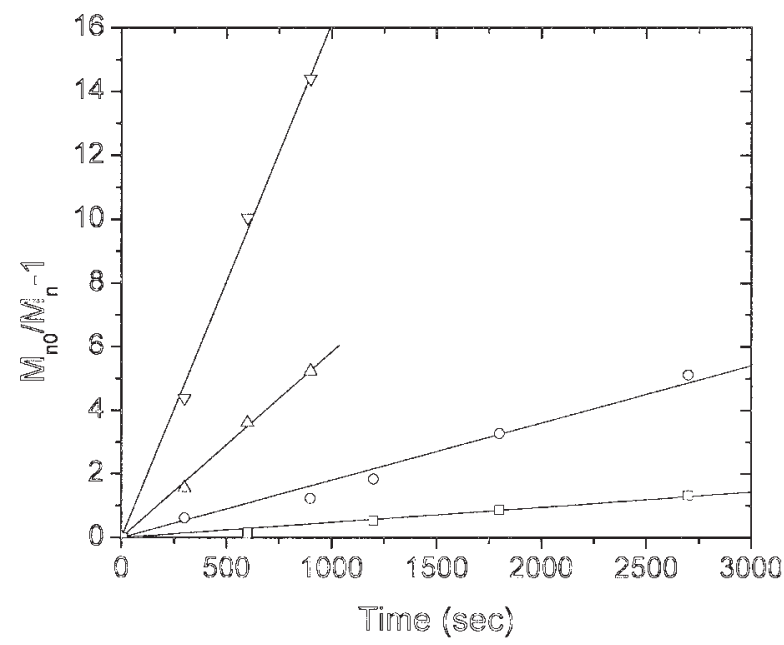

(a)

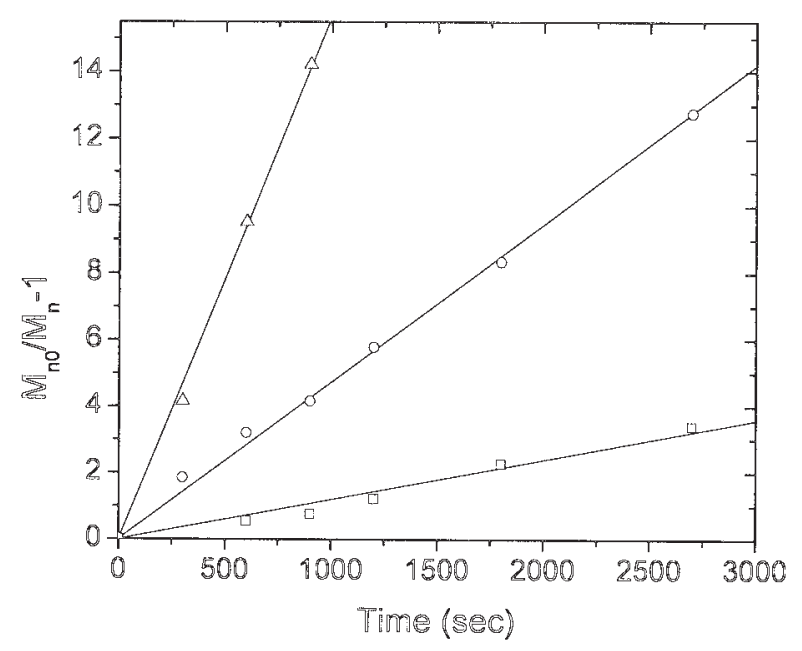

(b)

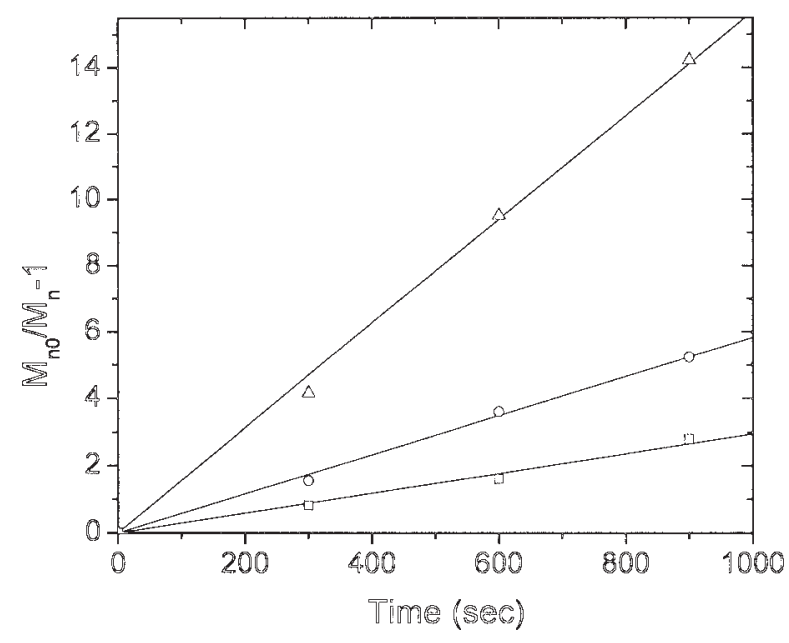

(c)

Figure $1(\mathrm{a}, \mathrm{b})$ Variation of $\left(M_{n 0} / M_{n}\right)-1$ with time $t$ at different temperatures with 0.4 or $1.0 \mathrm{~g} / \mathrm{L}$ persulfate, respectively: ( $\mathbf{\square})$ 40, ( $50,(\boldsymbol{\Delta})$ 60, and $(\boldsymbol{\nabla}) 70^{\circ} \mathrm{C}$. (c) Variation of $\left(M_{n 0} / M_{n}\right)-1$ with time $t$ with different concentrations of persulfate at $60^{\circ} \mathrm{C}$ : $(\mathbf{\square}) 0.2,(\mathbf{O}) 0.4$, and $(\boldsymbol{\Delta}) 1.0 \mathrm{~g} / \mathrm{L}$ persulfate.

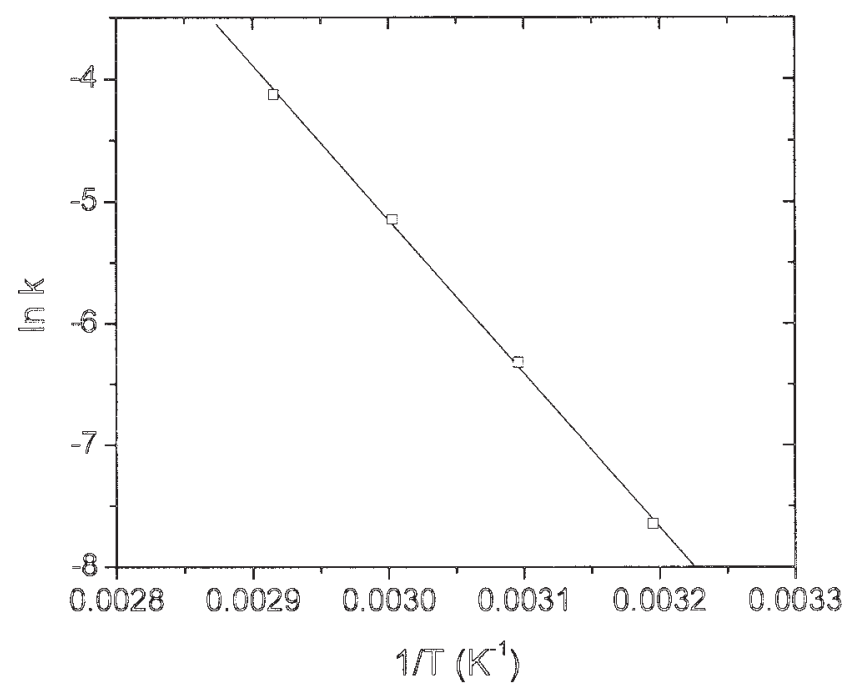

Figure 2 Variation of $k$ with the temperature $(T)$ at a 0.4 $\mathrm{g} / \mathrm{L}$ persulfate concentration.

varied from 10 to $20 \mathrm{~s}$, and at different concentrations of persulfate, which ranged from 0.2 to $1.0 \mathrm{~g} / \mathrm{L}$. When the polymer solution was exposed to microwave radiation in the presence of persulfate, rapid degradation occurred, whereas no degradation occurred in the absence of persulfate. The variation of $M_{n 0} / M_{n}$ with time for three different persulfate concentrations is shown in Figure 4(a-c). The rate of decrease was higher with a higher concentration of persulfate, and the degradation was rapid during the initial stages of irradiation. No degradation was observed at a 10-s cycle time with a $0.2 \mathrm{~g} / \mathrm{L}$ concentration of persulfate. The degradation accelerated by microwaves could be attributed to the volumetric heating of the sample and the improved mixing of the solution due to microstirring by the absorption of microwave energy by molecules. The

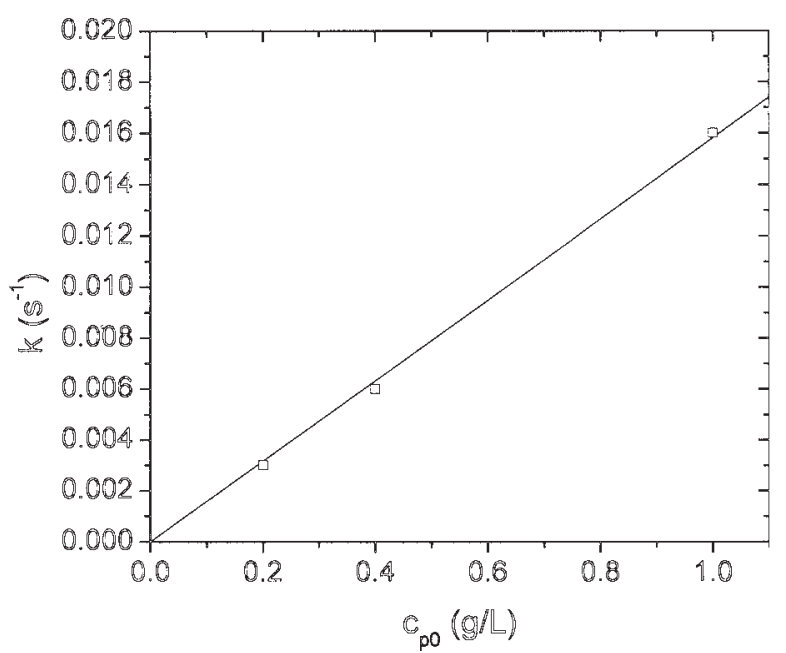

Figure 3 Variation of $k$ with $c_{p 0}$. 


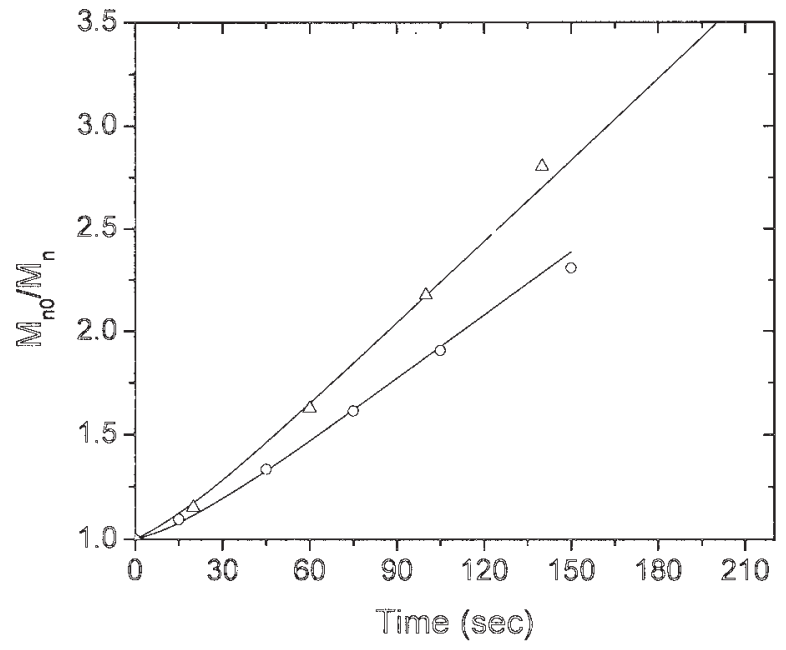

(a)

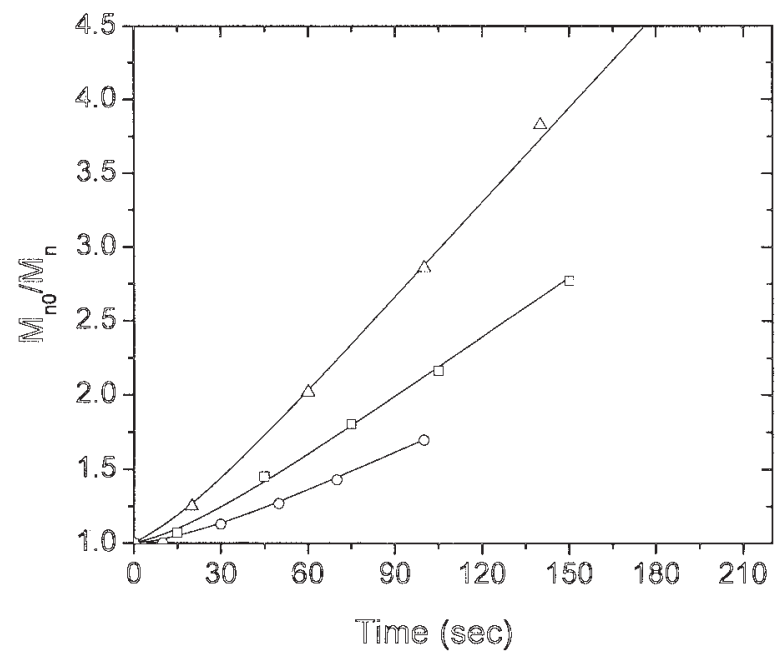

(b)

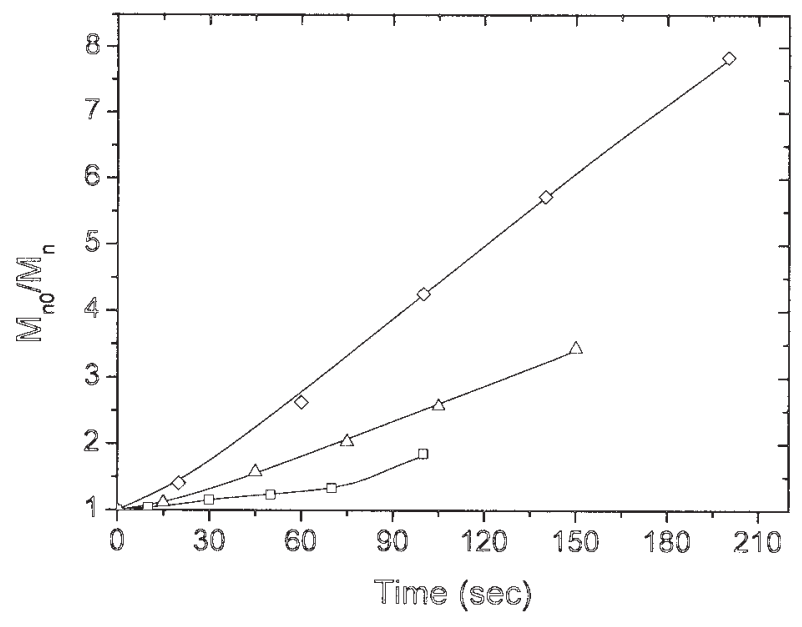

(c)

Figure 4 Variation of $M_{n 0} / M_{n}$ with time with (a) 0.2 , (b)

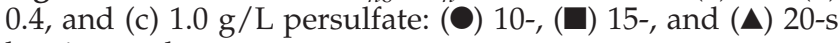
heating cycle. rate of radical formation was also enhanced because of inherently high temperatures produced in shorter times, which increased the overall rate of the degradation. The degradation of PEO in a microwave oven was compared with degradation by thermal heating. Thus, a solution with a persulfate concentration of 1 $\mathrm{g} / \mathrm{L}$ was taken and heated at the highest temperature reached in the microwave for a period of $2 \mathrm{~min}$. There was no significant degradation, and this clearly indicated that at comparable temperatures there existed a definite microwave effect that enhanced the rate of degradation.

The kinetic parameters for the degradation were obtained by nonlinear regression of the experimental data. The dependence of the rate coefficient on the temperature was assumed to be of an Arrhenius form. $k_{p}, k_{d}$ and $k_{\text {oxd }}$ were given by $k_{p}=k_{p 0} e^{-E_{p} / R T}, k_{d}=$ $k_{d 0} e^{-E_{d} / R T}$, and $k_{\text {oxd }}=k_{\text {oxdo } 0} e^{-E_{\text {oxd }} / R T}$. Because the rate coefficients were temperature-dependent, the temperature terms in the expressions were replaced by eq. (7). Because $k_{p}$ was given by $k_{p}=38.4 e^{-33,500 / R T}$, 11 the values for $k_{d}$ and $k_{\text {oxd }}$ were obtained by the solution of eqs. (4), (6), and (18) through the incorporation of the previous expressions for the rate coefficients and the temperature dependence of eq. (7). The initial conditions were set as $p^{(0)}(t=0)=p_{0}{ }^{(0)}, c_{p}(t=0)=c_{p 0}$, and $c(t=0)=0$. The nonlinearly regressed values of the rate coefficients were $k_{d}=19.0 e^{-7700 / T}$ and $k_{\text {oxd }}$ $=12.5 e^{-5200 / T}$. This indicated that the activation energies for $k_{d}$ and $k_{\text {oxd }}$ were 15.3 and $10.3 \mathrm{kcal} / \mathrm{mol}$, respectively. For Figure $4(\mathrm{a}-\mathrm{c})$, the data points were obtained from experiments, and the solid line was obtained by the fitting of the rate parameters of the model to the experimental data. There was good agreement between the model and experimental data. The rate coefficients obtained for the degradation of PEO in the presence of microwaves were significantly higher than those of the degradation caused by thermal heating.

\section{CONCLUSIONS}

The thermal and microwave-assisted oxidative degradation of PEO was studied with the addition of persulfate. The rate of degradation increased with the temperature, persulfate concentration, and heating cycle time. However, oxidative processes were mainly responsible for the polymer degradation because the thermal decomposition of persulfate was kinetically insignificant at temperatures lower than $50^{\circ} \mathrm{C}$. The rate coefficients were obtained from a theoretical model with continuous distribution kinetics. A comparison of the results showed that microwave-assisted degradation was far more effective than conventional thermal degradation in solution. Lower activation energies, higher rates, and reduced reaction times are the attractive features that microwave-assisted degrada- 
tion offers, and so it is a viable approach for polymer degradation.

\section{References}

1. Sato, S.; Murakata, T.; Baba, S.; Saito, Y.; Watanabe, S. J Appl Polym Sci 1990, 40, 2065.

2. Murakata, T.; Saito, Y.; Yosikawa, T.; Suzuki, T.; Sato, S. Polymer 1993, 34, 1436.

3. Madras, G.; Smith, J. M.; McCoy, B. J. Polym Degrad Stab 1997, 57, 131.

4. Madras, G.; Smith, J. M.; McCoy, B. J. Ind Eng Chem Res 1996, $52,349$.

5. Gedye, R.; Smith, F.; Westaway, K.; Ali, H.; Baldisera, L.; Laberge, L.; Rousell, J. Tetrahedron Lett 1986, 27, 279.

6. Giguere, R. J.; Bray, T. L.; Duncan, S. M. Tetrahedron Lett 1986, 27, 4945.

7. Ludlow-Palafox, C.; Chase, H. A. Ind Eng Chem Res 2001, 40, 4749.

8. Technical Information on Persulfates. http://www.fmcchemicals. com/Content/CPG/Images/AOD_Brochure_Persulfate.pdf (accessed Mar 2005).

9. Levitt, L. S.; Malinowski, E. R. J Am Chem Soc 1955, 77, 4517.

10. Howard, E.; Levitt, L. S. J Am Chem Soc 1953, 75, 6170.

11. Kolthoff, I. M.; Miller, I. K. J Am Chem Soc 1951, 73, 3055.

12. Bandyopadhyay, M.; Konar, R. S. J Ind Chem Soc 1974, 51, 722.
13. Beylerian, N. M.; Vardanyan, L. R.; Harutyunyan, R. S.; Vardanyan, R. L. Macromol Chem Phys 2002, 203, 212.

14. Odian, G. Principles of Polymerization; Wiley: New York, 1991.

15. da Trindade Neto, C. G.; Pereira, M. R.; Fonseca, J. L. C. Polym Degrad Stab 2002, 76, 227.

16. McGary, C. W. J Polym Sci 1960, 46, 51.

17. Caddick, S. Tetrahedron 1995, 51, 10403.

18. Correa, R.; Gonzalez, G.; Dougar, V. Polymer 1998, 39, 1471.

19. Chan, R. W. C.; Krieger, B. B. J Appl Polym Sci 1981, 26, 1533.

20. Allan, G. G.; Krieger, B. B.; Donald, W. J Appl Polym Sci 1980, 25, 1839.

21. Mallakpour, S. E.; Hajipour, A. R.; Mahdavian, A. R.; Zadhoush, A.; Hosseini, F. A. Eur Polym J 2001, 37, 1199.

22. Khan, A. R.; Johnson, J. A.; Robinson, R. J. Cereal Chem 1979, 56, 303.

23. Albi, T.; Lanzon, A.; Guinda, A.; Leon, M.; Perez-Camino, M. C. J Agric Food Chem 1997, 45, 3795.

24. Mallon, F. K.; Ray, W. H. J Appl Polym Sci 1998, 69, 1203.

25. Zhang, C.; Liu, L. J.; Zhuo, R. X. J Polym Sci Part A: Polym Chem 2003, 41, 13 .

26. Jacob, J.; Chia, L. H. L.; Boey, F. Y. C. J Appl Polym Sci 1996, 63, 787.

27. Sivalingam, G.; Agarwal, N.; Madras, G. AIChE J 2003, 49, 1821.

28. Vijayalakshmi, S. P.; Madras, G. Polym Degrad Stab 2004, 84, 341.

29. Madras, G.; Chattopadhyay, S. Chem Eng Sci 2001, 56, 5085.

30. Price, G. J.; Clifton, A. A. Polymer 1996, 37, 3971. 